\title{
Prescritibilidade das ações de ressarcimento ao erário fundadas em decisões dos Tribunais de Contas: uma análise jurídica
}

Prescriptibility of actions for reimbursement to the treasury based on decisions of the Courts of Auditors: a legal analysis

\section{Fernando Souza Abreu Júnior ${ }^{1}$}

\section{RESUMO}

O presente artigo objetiva suscitar uma análise jurídica das decorrências advindas da prescritibilidade da pretensão de ressarcimento ao erário baseadas em decisões dos Tribunais de Contas, conforme recente julgamento do Recurso Extraordinário ${ }^{0}$ 636.886/AL, com repercussão geral reconhecida (Tema 899). Para a consecução da pesquisa foi utilizada a metodologia bibliográfica mediante análise doutrinária, perquirindo-se especialmente os julgados exarados pelo Supremo Tribunal Federal (STF) e pelo Tribunal de Contas da União (TCU). A referida decisão do STF alterou o entendimento então pacificado nas Cortes de Contas de que as ações de ressarcimento ao erário eram imprescritíveis. Contudo, a Suprema Corte não abortou questões jurídicas inerentes às aludidas ações, tais como o termo inicial da contagem do prazo prescricional e o alcance da prescrição, se incidem nos processos de tomada de contas especial ou somente nas ações judiciais de ressarcimento, quesitos que podem ensejar insegurança jurídica tanto aos Tribunais de Contas e à Advocacia Geral da União quanto aos administrados. Dessa forma, imprescindível o debate acerca do tema, averiguando-se os caminhos que podem ser trilhados para a melhor resolução da questão, até a derradeira uniformização dos procedimentos intrínsecos às ações de ressarcimento ao erário.

\footnotetext{
$1 \quad$ Mestre em Gestão Pública pela Universidade de Brasília (UnB). Especialista em Direito Público pela Faculdade Dom Bosco. Bacharel em Direito pela Universidade Estadual de Santa Cruz (UESC). Auditor da Fundação Universidade de Brasília. Advogado. E-mail: nandoabreuu@gmail.com
} 
Palavras-Chave: Prescrição. Ações de Ressarcimento ao Erário. Recurso Extraordinário $n^{\circ}$ 636.886. Tribunal de Contas.

\section{ABSTRACT}

This paper makes a legal analysis of the consequences arising from prescribing the claim for reimbursement to the treasury based on decisions of the Courts of Auditors, according to a recent trial of Extraordinary Appeal $\mathrm{n}^{\mathrm{o}}$. 636,886, with recognized general repercussion (Theme 899). For such, a bibliographic search was conducted following doctrinal analysis to investigate those judged by the Brazilian Supreme Federal Court (STF) and the Federal Court of Accounts (TCU). The decision by the STF altered the understanding then settled in the Courts of Accounts that the actions for reimbursing the treasury were impossible to prescribe. However, the Supreme Court did not address legal issues inherent to the aforementioned actions, such as the initial term of the statute of limitations period and its scope, whether they affect the special accountability processes or only redress lawsuits, matters that may provide legal uncertainty both to the Courts of Accounts and to the Federal Attorney General and to those administered by them. Thus, discussing the subject is essential, ascertaining the paths that can be taken to the best resolution of the issue, until the ultimate standardization of the procedures are intrinsic to the actions for reimbursing the treasury.

Keywords: Prescription. Reimbursement actions to the treasury. Extraordinary Appeal $n^{\circ}$. 636.886. Brazilian Court of Accounts.

Recebido: 09-08-2020

Aprovado: 27-09-2020 


\section{INTRODUÇÃO}

Prefacialmente, ressalta-se que, nos termos do artigo 70 da Constituição federal de 1988, as fiscalizações contábil, financeira, orçamentária, operacional e patrimonial da União e das entidades da administração direta e indireta, quanto à legalidade, legitimidade, economicidade, aplicação das subvenções e renúncia de receitas, será exercida pelo Congresso Nacional, mediante controle externo, e pelo sistema de controle interno de cada Poder (BRASIL, 1988, artigo 70).

Quanto à competência de auxiliar o Congresso Nacional no exercício do controle externo, o artigo 71, II da Magna Carta assevera que compete ao Tribunal de Contas da União, dentre outras incumbências, o julgamento das contas daqueles que derem causa à perda, extravio ou outra irregularidade de que resulta prejuízo ao erário público.

Ressalta-se que as decisões de imputação de débito exaradas pelo Tribunal de Contas possuem eficácia de título executivo, conforme disposição do artigo $71, \S 3^{\circ}$ da $C F / 88$. Dessa forma, entende-se que a responsabilidade e o quantum devido já se encontra devidamente apurado, migrando diretamente para a fase de execução judicial - sendo esse pleito executório incumbência da Advocacia-Geral da União, no âmbito da União, e das respectivas Procuradorias, para os demais entes políticos.

O cerne do Recurso Extraordinário $n^{\circ}$ 636.886/AL, da Suprema Corte, refere-se à fase de execução da ação de ressarcimento ao erário baseada em decisão de Tribunal de Contas (BRASIL, 2020x). Antes, não havia prazo determinado para a Advocacia-Geral da União (ou respectiva procuradoria do ente) ingressar com a ação de execução. Entretanto, após o novel julgamento do STF, com tese de repercussão geral, a pretensão do ressarcimento ao erário encontrou limite temporal, tornando-se prescritível.

O presente artigo objetiva, portanto, tecer uma análise jurídica das decorrências advindas da prescritibilidade da pretensão de ressarcimen- 
to ao erário baseadas em decisões dos Tribunais de Contas, consoante o julgamento do Recurso Extraordinário no 636.886/AL, com repercussão geral reconhecida (Tema 899).

Para este desiderato, a pesquisa encontra-se assentada nos seguintes questionamentos: quais as implicações decorrentes da decisão do STF nos autos do Recurso Extraordinário nº 636.886/AL (tema 899)? Qual o termo inicial da contagem do prazo? Em relação ao seu alcance, abrange os processos de tomada de contas especial ou apenas as ações judiciais de ressarcimento ao erário?

Em relação ao procedimento metodológico, trata-se de um estudo descritivo-analítico e exploratório, uma vez que almeja, concomitantemente, explicitar o problema suscitado, bem assim desenvolver juízo crítico acerca do objeto pesquisado, provendo-o de maiores informações para o alcance de uma resolução plausível a ser adotada pelos distintos Tribunais de Contas do país.

Por seu turno, a justificativa para este trabalho reside na contemporaneidade do objeto, nas lacunas do julgamento do Supremo Tribunal Federal e na sua caracterização como tema de repercussão geral, além da constituição de um novo paradigma para as Cortes de Contas (já que o julgado apresentou uma interpretação distinta daquela que se encontrava pacificada na jurisprudência dos tribunais), bem assim em função da omissão quanto aos institutos da prescrição e decadência no âmbito das leis orgânicas de diversos Tribunais de Contas, a exemplo da lacuna verificada na Lei Orgânica do Tribunal de Contas da União (Lei no 8.443/1992).

Ressalta-se que os Tribunais de Contas defendiam a imprescritibilidade das ações de ressarcimento ao erário, amparando-se, para tanto, no artigo $37, \S 5^{\circ}$ da Constituição federal de 1988 , ao dispor que "A lei estabelecerá os prazos de prescrição para ilícitos praticados por qualquer agente, servidor ou não, que causem prejuízos ao erário, ressalvadas as respectivas ações de ressarcimento.” (BRASIL, 1988). 
Com este pressuposto, a interposição da execução judicial da ação de ressarcimento ficava ao alvedrio dos órgãos de controle e das procuradorias dos respectivos entes políticos ou da Advocacia-Geral da União, na hipótese de a ação ser incumbência da União.

Dessa forma, se o agente, cuja sanção fora cominada pelo acórdão do Tribunal de Contas, não quitar o débito de forma voluntária e não for possível a consecução dos descontos diretamente nos vencimentos/ proventos do imputado, exsurgirá a necessidade de executar a decisão no âmbito judicial, uma vez que as Cortes de Contas não possuem competência para a impor a execução de suas deliberações (FERNANDES, 2015).

Contudo, a segurança jurídica da prescritibilidade era sempre pauta de discussão, sendo utilizada como fundamento pelo Supremo Tribunal Federal, no julgamento do Recurso Extraordinário no 669.069 (Tema 666), datado de 2016, quando foi firmada a tese de que é prescritível a ação de reparação de danos à Fazenda Pública decorrente de ilícito civil, bem assim nos autos do Recurso Extraordinário no 852.475/SP (Tema 897), datado de 2019, quando foi consolidada a tese de que as ações de ressarcimento ao erário baseadas na prática de ato doloso tipificado na Lei de Improbidade Administrativa são imprescritíveis. Nesse vértice, os atos de improbidade advindos de conduta culposa não estariam subsumidos a esta hipótese, sendo, portanto, prescritíveis.

No julgamento do Recurso Extraordinário $n^{\circ}$ 636.886/AL, analisado neste estudo, o Supremo seguiu entendimento similar ao esposado nos Temas 666 e 897, com as devidas adequações, pautando-se pela prescritibilidade das ações de ressarcimento ao erário derivadas de decisões dos Tribunais de Contas. O ministro Alexandre de Moraes, relator do referido Recurso, apresentou a seguinte tese:

1. A regra de prescritibilidade no Direito brasileiro é exigência dos princípios da segurança jurídica e do devido processo legal, o qual, em seu sentido material, deve garantir efetiva e real proteção contra o exercício do arbítrio, com a imposição de res- 
trições substanciais ao poder do Estado em relação à liberdade e à propriedade individuais, entre as quais a impossibilidade de permanência infinita do poder persecutório do Estado.

2. Analisando detalhadamente o tema da "prescritibilidade de ações de ressarcimento", este SUPREMO TRIBUNAL FEDERAL concluiu que, somente são imprescritíveis as ações de ressarcimento ao erário fundadas na prática de ato de improbidade administrativa doloso tipificado na Lei de Improbidade Administrativa - Lei 8.429/1992 (TEMA 897). Em relação a todos os demais atos ilícitos, inclusive àqueles atentatórios à probidade da administração não dolosos e aos anteriores à edição da Lei 8.429/1992, aplica-se o TEMA 666, sendo prescritível a ação de reparação de danos à Fazenda Pública.

3. A excepcionalidade reconhecida pela maioria do SUPREMO TRIBUNAL FEDERAL no TEMA 897, portanto, não se encontra presente no caso em análise, uma vez que, no processo de tomada de contas, o TCU não julga pessoas, não perquirindo a existência de dolo decorrente de ato de improbidade administrativa, mas, especificamente, realiza o julgamento técnico das contas à partir da reunião dos elementos objeto da fiscalização e apurada a ocorrência de irregularidade de que resulte dano ao erário, proferindo o acórdão em que se imputa o débito ao responsável, para fins de se obter o respectivo ressarcimento.

4. A pretensão de ressarcimento ao erário em face de agentes públicos reconhecida em acórdão de Tribunal de Contas prescreve na forma da Lei 6.830/1980 (Lei de Execução Fiscal)

5. Recurso Extraordinário DESPROVIDO, mantendo-se a extinção do processo pelo reconhecimento da prescrição. Fixação da seguinte tese para o TEMA 899: "É prescritivel a pretensão de ressarcimento ao erário fundada em decisão de Tribunal de Contas" (BRASIL, 2020, Ementa oficial).

Na decisão supracitada, o douto ministro salientou que não estava diante da excepcionalidade referida no Tema 897, uma vez que o Tribunal de Contas não analisa culpa e dolo de atos administrativos ímprobos, estabelecendo, dessa forma, a prescritibilidade das referidas ações, sem, contudo, apresentar delineamentos jurídicos decorrentes da decisão. 


\section{A PRESCRIÇÃO COMO FUNDAMENTO DE SEGURANÇA JURÍDICA}

A prescrição constitui um objeto de direito material que visa prover efetividade e estabilidade às relações jurídico-sociais, relacionando-se diretamente ao princípio da segurança jurídica e à ordem pública. No âmbito dos Tribunais de Contas, e nos termos abordados na presente análise, a prescrição denota a extinção, por inércia da Administração Pública, do direito ao ressarcimento dos recursos descentralizados que foram malversados.

Ainda em relação à conceituação jurídica da prescrição, o ministro Luís Roberto Barroso, ao sustentar seu voto no julgamento do Mandado de Segurança $n^{\circ}$ 32.201/DF, consignou que "a prescrição é instituto diretamente ligada ao princípio geral da segurança das relações jurídicas, que tem por decorrência, salvo hipóteses excepcionais, a regra da prescritibilidade, em qualquer ramo jurídico" (BRASIL, 2017, p. 5).

A Constituição federal de 1988 explicita as hipóteses de exceção à imprescritibilidade, logo, pode-se considerar que a regra do ordenamento jurídico brasileiro é a prescritibilidade. Ressalta-se que a jurisprudência das Cortes de Contas tem apresentado entendimentos diversos, tornando plausível e contemporânea, portanto, a discussão acerca da prescrição da pretensão estatal em ação de ressarcimento ao erário decorrente de decisão de Tribunal de Contas.

Lôbo (2013) defende que a incidência da prescrição extingue a pretensão do direito subjetivo, elidindo, ante a inércia e o decurso do tempo, a faculdade de demandá-lo em Juízo em face do sujeito que o descumpriu. Essa assertiva é corroborada pelo catedrático José Afonso da Silva (2012, p. 682) ao sustentar que:

A prescritibilidade, como forma de perda da exigibilidade de direito, pela inércia de seu titular, é um princípio geral do di- 
reito. Não será, pois, de estranhar que ocorram prescrições administrativas sob vários aspectos, quer quanto às pretensões de interessados em face da Administração, quer quanto às destas em face dos administrados.

Couto e Silva (2005) defendem que a segurança jurídica e o princípio da confiança constituem subsídios conservadores insertos no ordenamento jurídico brasileiro, visando, de forma precípua, inibir eventuais alterações do direito positivo ou da atuação estatal. Denota-se, assim, que a segurança jurídica se relaciona diretamente ao Estado Democrático de Direito, instituindo fronteiras, inclusive temporais, à sua própria atuação.

Na seara cível, a prescrição encontra-se prevista no Título IV, Capítulo I do Código Civil de 2002, nos termos do seu artigo 189. O mesmo diploma legal, em seu artigo 205, estabelece que a prescrição ocorre, em regra, no prazo de dez anos, desde que a lei não fixe prazo menor.

O ministro Luís Roberto Barroso, nos autos do julgamento do Recurso Extraordinário $n^{\circ}$ 669.069/MG (Tema 666) salientou que as exceções inequívocas à prescritibilidade são aquelas dispostas na Constituição federal de 1988, quais sejam o crime de racismo e as ações de grupos armados contra o Estado.

Reitera-se, como já dito anteriormente, que a Constituição federal de 1988 dispôs, em seu artigo 37, § 5º que "a lei estabelecerá os prazos de prescrição para ilícitos praticados por qualquer agente, servidor ou não, que causem prejuízos ao erário, ressalvadas as respectivas ações de ressarcimento" (BRASIL, 1988). Depreende-se, assim, que esta norma possui eficácia limitada, carecendo de regulamentação infraconstitucional para se tornar plenamente operativa, nos termos defendidos por Souza Neto e Sarmento (2012).

Neste ínterim, o legislador infraconstitucional, fundado no seu múnus, exarou a Lei $\mathrm{n}^{\circ}$ 8.429, de 2 de junho de 1992 (Lei de Improbidade Administrativa), estabelecendo o prazo prescricional de cinco anos para as 
ações de improbidade administrativa.

Ressalta-se, nesse diapasão, que as decisões da Excelsa Corte, tanto nos Recursos Extraordinários $n^{0} 669.069$ e $n^{\circ} 852.475 / \mathrm{SP}$, quanto no $n^{\circ}$ 636.886/AL, não demarcaram o prazo prescricional para os Tribunais de Contas, assentando, entretanto, que tal delimitação deve ser estipulada mediante legislação infraconstitucional.

Quanto à interpretação ao artigo $37, \S 5^{\circ}$ da Constituição federal de 1988, imprescindível destacar a mudança de entendimento do catedrático Celso Antônio Bandeira de Melo, tendo sustentado seu novo posicionamento nos seguintes termos:

Até a $26^{\mathrm{a}}$ edição deste Curso, admitimos que, por força do $\S 5^{\circ}$ do Artigo 37, de acordo com o qual os prazos de prescrição para ilícitos causados ao erário serão estabelecidos por lei, ressalvadas as respectivas ações de ressarcimento, estas últimas seriam imprescritíveis. É certo que aderíamos a tal entendimento com evidente desconforto, por ser óbvio o desacerto de tal solução normativa. [...] Como explicar então o alcance do Artigo 37, § $5^{\circ}$ ? Pensamos que o que se há de extrair dele é a intenção manifesta, ainda que mal expressada, de separar os prazos de prescrição do ilícito propriamente, isto é, penal, ou administrativo, dos prazos de ações de responsabilidade, que não terão porque obrigatoriamente coincidir. Assim, a ressalva para as ações de ressarcimento significa que terão prazos autônomos em relação aos que a lei estabelecer para as responsabilidades administrativas e penais (MELO, 2010, p. 1064-1065).

Observa-se que os julgados do Supremo Tribunal Federal abordados no presente estudo seguem a mesma linha sustentada pelo excelso doutrinador. Dessa forma, verifica-se a tendência jurídica doutrinária e jurisprudencial em assentar a prescritibilidade das ações de ressarcimento ao erário, assegurando, de tal forma, a primazia da segurança e estabilidade das relações jurídicas. 


\section{TERMO A $Q U O$ DA CONTAGEM DO PRAZO PRESCRICIO- NAL DAS AÇÕES DE RESSARCIMENTO AO ERÁRIO}

Nos termos supratranscritos, é cediço que a Constituição federal de 1988, em seu artigo $37, \S 5^{\circ}$, estabelece que a legislação infraconstitucional estabelecerá os prazos prescricionais para ilícitos que causem prejuízo ao erário, ressalvando, contudo, as respectivas ações de ressarcimento.

Por sua vez, a Súmula n 282 do Tribunal de Contas da União apresenta a mesma premissa, ao estabelecer que "as ações de ressarcimento movidas pelo Estado contra os agentes causadores de danos ao erário são imprescritíveis" (BRASIL, 2012b). Dessa forma, depreende-se que a incumbência de estabelecer o prazo prescricional é da legislação infraconstitucional. Entretanto, a Lei n ${ }^{\circ} 8.443 / 1992$ - a Lei Orgânica do Tribunal de Contas da União, por exemplo, não apresentou limite temporal. Assim, o entendimento que vigorava, até então, era de que os danos causados ao erário eram imprescritíveis.

No que concerne à pretensão punitiva, o Tribunal de Contas da União, com o fito de uniformizar a jurisprudência, exarou o Acórdão 1441/2016 - Plenário, formando duas correntes interpretativas: a primeira sustenta que a pretensão punitiva da Corte se sujeita ao prazo prescricional geral estipulado no artigo 205 do Código Civil, qual seja, 10 (dez) anos, sendo o marco inicial a data da ocorrência da irregularidade sancionada, conforme artigo 189 do mesmo diploma legal. A segunda corrente defende que o prazo prescricional é de 5 (cinco) anos, conforme as normas de direito público, sendo o termo a quo a ciência dos fatos pela Corte de Contas.

O recente Acórdão $n^{\circ}$ 1172/2020 -Plenário, do Tribunal de Contas da União, fazendo menção ao Acórdão no 1441/2016 - Plenário, apresentou excertos elucidativos para a discussão, tanto quanto ao termo inicial da prescrição no âmbito do Tribunal de Contas quanto à sua regulamentação, consoante excerto abaixo transcrito: 
10.1. Nos termos desse Acórdão, que uniformizou a jurisprudência do TCU a respeito, a pretensão punitiva subordina-se ao prazo prescricional geral de dez anos indicado no artigo 205 do Código Civil, contado a partir da data da ocorrência da irregularidade e interrompido pelo ato que ordenar a citação, a audiência ou a oitiva da parte. [...]

12.1. Na linha do que foi decidido pela $1^{\text {a }}$ Turma do STF ao julgar o MS 32.201, também se entende que 'a prescrição da pretensão punitiva do TCU é regulada integralmente pela Lei no 9.873/1999' (TCU, 2020a).

O Acórdão do STF prolatado nos autos do Mandado de Segurança $\mathrm{n}^{\mathrm{o}} 32.201 / 2017$-Primeira Turma possui posicionamento contundente em relação à regulamentação da prescrição da pretensão administrativa sancionadora do Tribunal de Contas da União, asseverando que incumbe, integralmente, à Lei n ${ }^{\circ}$ 9.873/1999 tal desiderato, seja por aplicação direta ou por analogia.

Há que se ressaltar, contudo, que o Tribunal de Contas constitui uma instituição independente, não integrando a Administração Pública - ou seja, não perfaz a formação dos Poderes Executivo, Legislativo ou Judiciário. Dessa forma, perfilha-se o entendimento que não há embasamento para a aplicação direta, no âmbito do Tribunal de Contas, de norma cuja aplicabilidade se encontra adstrita à Administração Pública federal.

O Tribunal de Contas da União (BRASIL, 2008), nos autos do Acórdão no 49/2008 - Primeira Câmara, salientou que o prazo prescricional previsto na Lei $n^{\circ}$ 9.873/1999 não possui aplicação direta aos processos de tomada de contas especial, uma vez que o embasamento da referida legislação é o exercício do Poder de Polícia, diferindo, portanto, das atividades de controle externo, que configuram, em sua essência, atos de gestão.

Todavia, sua aplicação por analogia não possui qualquer óbice legal. Ao contrário, encontra respaldo na Lei de Introdução às normas do Direito Brasileiro. Essa colmatação se sustenta, sobretudo, na identidade dos regimes em questão - ambos de direito público - bem assim na simi- 
laridade de sua instituição, qual seja estabelecer prazo de prescrição para o exercício de ação punitiva pela Administração Pública Federal, direta e indireta.

No julgamento do Recurso Extraordinário no 636.886/AL, o STF firmou o entendimento de que a pretensão de ressarcimento ao erário emanada de decisão de Tribunal de Contas prescreve nos termos da Lei $n^{0} 6.830 / 1980$. Nessa ótica, ao seguir os procedimentos da Lei de Execução Fiscal, a Corte excelsa abordou prescrição inserta em processo de execução judicial do Acórdão do Tribunal de Contas, não se referindo à prescrição da pretensão relativa ao controle externo.

No que concerne a esse quesito, nos autos do Acórdão n ${ }^{\circ}$ 6.589/2020 - Segunda Câmara, o Tribunal de Contas União apresentou a seguinte deliberação:

Claramente, o Recurso Extraordinário sob enfoque tratou de prescrição que ocorreu na fase de execução judicial do acórdão condenatório desta Corte de Contas, e não da prescrição da pretensão de ressarcimento associada a processo de controle externo.

É bom frisar ainda que, nos termos da tese firmada pelo STF no RE 636.886, só após o trânsito em julgado do acórdão condenatório do TCU é que terá início a contagem do prazo prescricional para a execução judicial desse título pela Advocacia Geral da União (AGU) (BRASIL, 2020b).

Dessa forma, a partir do excerto acima, depreende-se que o termo a quo do prazo prescricional nos processos de execução judicial do título executivo formado a partir de decisão de Tribunal de Contas dar-se-á apenas após o trânsito em julgado do respectivo acórdão condenatório exarado pelo Tribunal de Contas, sendo este o entendimento mais contemporâneo. 


\section{ALCANCE DA PRESCRIÇÃO: PROCESSOS DE TOMADA DE CONTAS ESPECIAL E AÇÕES JUDICIAIS DE RESSARCIMENTO}

A Tomada de Contas Especial constitui um processo administrativo, formalizado com rito próprio, que visa investigar a apuração dos fatos, a quantificação do dano, a identificação dos responsáveis pela ocorrência de dano à Administração Pública Federal, possibilitando seu respectivo ressarcimento conforme intelecção do artigo $2^{\circ}$, caput, da Instrução Normativa do TCU n ${ }^{0}$ 71/2012 (BRASIL, 2012a). Assim, o pressuposto para a instauração do processo de tomada de contas especial é a ocorrência de prejuízo ao erário.

O Superior Tribunal de Justiça, nos autos do Recurso Especial $\mathrm{n}^{\mathrm{o}}$ 1.480.350/RS, datado de 5 de abril de 2016, salientou que a tomada de contas especial não corresponde à ação de ressarcimento ao erário, não incidindo, portanto, a imprescritibilidade disposta no artigo $37, \S 5^{\circ}$ da Constituição federal de 1988. A referida Corte ressaltou que a imprescritibilidade alcança somente a ação de ressarcimento ao erário ajuizada perante o Poder Judiciário.

Dessa forma, segundo o STJ, a instauração de tomada de contas especial segue o prazo prescricional quinquenal, aplicando-se, por analogia, a Lei n ${ }^{\circ}$ 9.873/1999 e o Decreto $n^{\circ}$ 20.910/1932. Entretanto, ressaltase que a imprescritibilidade em questão constitui matéria constitucional, razão pela qual não incumbe à referida Corte o julgamento em relação ao seu alcance, mas sim ao Supremo Tribunal Federal.

O TCU, no Acórdão $n^{\circ} 1482 / 2020$, salientou que haverá a subsunção da Lei de Improbidade Administrativa (Lei no 8.429/1992) caso a ausência injustificada da prestação de contas seja caracterizada como ato doloso; restando, portanto, configurada a imprescritibilidade da pretensão de ressarcimento ao erário. 
Nesse ínterim, ressalta-se que o Recurso Extraordinário nº 636.886/ AL abordou a prescrição nos autos de processo de execução judicial do Acórdão sancionatório do Tribunal de Contas, não tratando da pretensão de ressarcimento atinente, especificamente, ao controle externo.

Entendimento similar pode ser verificado no julgamento do Recurso Extraordinário $n^{\circ}$ 669.069/MG (Tema de repercussão geral 666), quando a Suprema Corte enunciou que o reconhecimento da prescrição das ações de ressarcimento ao erário não atinge os processos de controle externo, haja vista que, no caso sob análise, a decisão apenas se aplicaria às ações de reparação de danos à Fazenda Pública decorrente de ilícito civil (BRASIL, 2016).

No mesmo compasso, o julgamento do Recurso Extraordinário $\mathrm{n}^{\circ} 852.475 / \mathrm{SP}$ firmou a tese de que as ações de ressarcimento ao erário advindas de atos dolosos tipificados na Lei de Improbidade Administrativa (Lei $\left.n^{\circ} 8.429 / 1992\right)$, não atinge os processos de controle externo, pois esses não decorrem, precipuamente, de ações de improbidade administrativa.

O Acórdão n ${ }^{\circ}$ 1267/2019 - Plenário, do Tribunal de Contas da União, corrobora os posicionamentos supracitados ao asseverar que:

A suspensão pelo STF das demandas nas quais esteja em questão a prescritibilidade da pretensão de ressarcimento ao erário com base em decisão de tribunal de contas (RE 636.886/STF) alcança tão somente a fase judicial de cobrança do título extrajudicial, não atingindo os processos de controle externo em trâmite. Até julgamento definitivo em contrário pelo STF, permanece o entendimento do TCU acerca da imprescritibilidade das pretensões de ressarcimento decorrentes de tomadas de contas especiais (BRASIL, 2019).

No mesmo ensejo, o Acórdão no 6.589/2020 - Segunda Câmara, com sessão datada de 16 de junho de 2020, deliberou que: 
o entendimento proferido pelo STF no RE 636.886 (tema 899), a respeito da prescritibilidade da pretensão de ressarcimento ao erário com base em decisão de tribunal de contas, alcança tão somente a fase judicial de execução do título extrajudicial, não atingindo os processos de controle externo em trâmite no TCU (BRASIL, 2020b).

Desta forma, observa-se que a jurisprudência do Tribunal de Contas da União já possui entendimento firmado que supre a lacuna referente ao alcance da prescritibilidade da pretensão de ressarcimento ao erário fundada em decisão de Tribunal de Contas. Nesse entendimento, a prescrição se refere apenas à fase de execução judicial do título executivo.

\section{CONSIDERAÇÕES FINAIS}

A prescritibilidade das ações de ressarcimento ao erário fundadas em decisões dos Tribunais de Contas tem suscitado diversas controvérsias, especialmente em face da ausência de norma específica que regule a prescrição em prol dos jurisdicionados no âmbito destes Tribunais.

O Supremo Tribunal Federal, no julgamento do Recurso Extraordinário $n^{\circ}$ 636.886/AL, reafirmou o entendimento de que apenas são imprescritíveis as ações de ressarcimento ao erário fundadas em ato doloso tipificadas na Lei de Improbidade Administrativa.

Assim, à luz do entendimento da Excelsa Corte, não há que se falar em interpretação extensiva do artigo $37, \S 5^{\circ}$ da Constituição federal, mantendo-se, portanto, a regra do ordenamento jurídico brasileiro, qual seja a prescritibilidade das ações de ressarcimento ao erário, adotando-se a Lei $n^{\circ}$ 9.873/1999 como baliza legal mais propícia para aplicação da prescrição das ações de ressarcimento ao erário baseadas em decisões de Tribunal de Contas.

Quanto ao termo inicial da contagem do prazo prescricional para a ação de ressarcimento ao erário fundada em decisão de Tribunal de Con- 
tas, o entendimento prevalecente, atualmente, é que o termo inicial corresponde ao trânsito em julgado do acórdão condenatório prolatado pelo respectivo Tribunal de Contas.

No que concerne ao alcance da aludida prescrição, é razoável que as Cortes de Contas dos diversos entes adotem o posicionamento exarado pelo Tribunal de Contas da União no Acórdão no 6.589/2020 - Segunda Câmara, segundo o qual a prescritibilidade da pretensão alcança tão somente a execução judicial do título, não abrangendo os processos de controle externo. Essa conjectura decorre especialmente do fato de o TCU ser órgão paradigma para os demais Tribunais de Contas, conforme previsão do artigo 75 da Constituição federal.

Dessa forma, seguindo o compasso da decisão do Supremo, imprescindível que os Tribunais de Contas, a Advocacia-Geral da União e as procuradorias competentes sopesem seus posicionamentos e adequem suas jurisprudências à interpretação constitucional proferida pelo Supremo Tribunal Federal, acolhendo, na fase de execução judicial, a prescritibilidade das ações de ressarcimento ao erário fundadas em suas decisões, assegurando, dessa forma, não apenas celeridade na tramitação dos processos, mas também maior segurança jurídica aos administrados.

\section{REFERÊNCIAS}

BRASIL. Constituição da República Federativa do Brasil de 1988. Brasília, DF: Senado, 1988. Disponível em: https://bit.ly/3n7C0uL. Acesso em: 5 ago. 2020.

BRASIL. Decreto ${ }^{\circ}$ 20.910, de 6 de janeiro de 1932. Regula a prescrição quinquenal. Diário Oficial da União, Brasília, DF, 8 jan. 1932, p. 371. Disponível em: https://bit.ly/3j2qE7Y. Acesso em: 5 ago. 2020. 
BRASIL. Lei $n^{\circ} 8.429$, de 2 de julho de 1992. Dispõe sobre as sanções aplicáveis aos agentes públicos nos casos de enriquecimento ilícito no exercício de mandato, cargo, emprego ou função na administração pública direta, indireta ou fundacional e dá outras providências. Diário Oficial da União, Brasília, DF, 3 jun. 1992, p. 6993. Disponível em: https://bit. ly/31dW4SS. Acesso em: 5 ago. 2020.

BRASIL. Lei $n^{\circ}$ 9.873, 23 de novembro de 1999. Estabelece prazo de prescrição para o exercício de ação punitiva pela Administração Pública Federal, direta e indireta, e dá outras providências. Diário Oficial da União, Brasília, DF, 24 nov. 1999, p. 3, Edição extra. Disponível em: https://bit.ly/2SZhPRC. Acesso em: 5 ago. 2020.

BRASIL. Lei n ${ }^{\circ} 10.406$, de 10 de janeiro de 2002. Institui o Código Civil. Diário Oficial da União, Brasília, DF, p. 1, 11 jan. 2002. Disponível em: https://bit.ly/33mCtRI. Acesso em: 5 ago. 2020.

BRASIL. Superior Tribunal de Justiça (1. Turma). Recurso Especial $n^{0}$ 1480350/RS 2014/0142962-8. Processual civil e administrativo. Recurso especial. Tribunal de Contas da União. Processo de tomada de contas especial. Violação a Instrução Normativa. Exame incabível em sede de apelo especial [...]. Relator: Min. Benedito Gonçalves. Brasília, DF: Supremo Tribunal de Justiça, 5 abr. 2016. Disponível em: https://bit. ly/2F3anSd. Acesso em: 27 jul. 2020.

BRASIL. Supremo Tribunal Federal (1. Turma). Acórdão no Mandado de Segurança no 32.201/DF. Direito administrativo. Mandado de segurança. Multas aplicadas pelo TCU. Prescrição da pretensão punitiva. Exame de legalidade. Relator: Min. Roberto Barroso. Brasília, DF: Supremo Tribunal Federal, 21 mar. 2017. Disponível em: https://bit.ly/3d8uMlC. Acesso em: 5 ago. 2020. 
BRASIL. Supremo Tribunal Federal (Tribunal Pleno). Acórdão no Recurso Extraordinário n⿳ 636.886/AL. Constitucional e administrativo. Repercussão geral. Execução fundada em acórdão proferido pelo Tribunal de Contas da União. Pretensão de ressarcimento ao erário. art. 37, § 50, da Constituição federal. Prescritibilidade. Relator: Min. Alexandre de Moraes. Brasília, DF: Supremo Tribunal Federal, 24 jun. 2020. Disponível em: https://bit.ly/3jzG4S6. Acesso em: 01 ago. 2020.

BRASIL. Supremo Tribunal Federal (Tribunal Pleno). Acórdão no Recurso Extraordinário n⿳ 669.069/MG. Relator: Min. Teori Zavascki. Brasília, DF: Supremo Tribunal Federal, 3 fev. 2016. Disponível em: https://bit.ly/2SqHzGx. Acesso em: 27 jul. 2020.

BRASIL. Supremo Tribunal Federal (Plenário Virtual). Acórdão no Recurso Extraordinário no 852.475/SP. Relator: Min. Alexandre de Moraes. Brasília, DF: Supremo Tribunal Federal, 8 ago. 2018. Disponível em: https://bit.ly/2GqcX5m. Acesso em: 27 jul. 2020.

BRASIL. Tribunal de Contas da União. Acórdão no 49/2008 - Primeira Câmara. Tomada de contas especial. Não-comprovação da correta aplicação dos recursos recebidos por meio de convênio. Contas irregulares. Débito. Relator: Min. Marcos Bemquerer. Brasília, DF: Tribunal de Contas da União, 29 jan. 2008. Disponível em: https://bit.ly/2GB2eok. Acesso em: 30 jul. 2020.

BRASIL. Tribunal de Contas da União. Acórdão n 1441/2016 - Plenário. Incidente de Uniformização de Jurisprudência a respeito da prescrição da pretensão punitiva do Tribunal de Contas da União. Relator: Ministro Benjamim Zymler. Brasília, DF: 8 jun. 2016. Disponível em: https://bit. ly/3cSuH58. Acesso em: 29 jul. 2020. 
BRASIL. Tribunal de Contas da União. Acórdão no 1267/2019 Plenário. Recursos de reconsideração interpostos contra acórdão que julgou irregulares as contas dos recorrentes, imputando-lhes débito e multas em razão de irregularidades nas obras de conservação e restauração na Rodovia BR-153/TO, trecho Wanderlândia-Xambioá/TO. Relator: Ministro Aroldo Cedraz. Brasília, DF, 5 jun. 2019. Disponível em: https:// bit.ly/3inMqCU. Acesso em: 29 jul. 2020.

BRASIL. Tribunal de Contas da União. Acórdão n 1172/2020 - Plenário. Relator: Ministro Aroldo Cedraz. Brasília, DF, 13 maio 2020a. Disponível em: https://bit.ly/3nbrimQ. Acesso em: 2 ago. 2020.

BRASIL. Tribunal de Contas da União. Acórdão $n^{\mathbf{0}} \mathbf{6 . 5 8 9 / 2 0 2 0}$ Segunda Câmara. Relator: Raimundo Carreiro. Brasília, DF, 16 jun. 2020b. Disponível em: https://bit.ly/33reilo. Acesso em: 2 ago. 2020.

BRASIL. Tribunal de Contas da União. Acórdão no $\mathbf{n}^{\mathbf{1}} \mathbf{4 8 2} / \mathbf{2 0 2 0}$ Plenário. Relator: Walton Alencar Rodrigues. Brasília, DF, 10 jun. 2020c. Disponível em: https://bit.ly/3nUrCqx. Acesso em: 2 ago. 2020.

BRASIL. Tribunal de Contas da União. Instrução Normativa $\mathrm{n}^{\circ} 71$, de 28 de novembro de 2012. Dispõe sobre a instauração, a organização e o encaminhamento ao Tribunal de Contas da União dos processos de tomada de contas especial. Diário Oficial da União, Brasília, DF, 5 dez. 2012a, p. 49.

BRASIL. Tribunal de Contas da União. Súmula 282. As ações de ressarcimento movidas pelo Estado contra os agentes causadores de danos ao erário são imprescritíveis. Relator: Min. Ana Arraes. Brasília, DF: Tribunal de Contas da União, 15 ago. 2012b. Disponível em: https://bit. 1y/2SjEw2y. Acesso em: 30 jul. 2020. 
COUTO E SILVA, A. O princípio da segurança jurídica (proteção à confiança) no direito público brasileiro e o direito da administração pública de anular seus próprios atos administrativos: o prazo decadencial do art. 54 da lei do processo administrativo da união (lei 9.784/99). Revista Eletrônica de Direito do Estado, Salvador, n. 2, v. 1, p. 27-28, 2005.

FERNANDES, J. U. J. Tomada de contas especial: processo e procedimento na administração pública e nos tribunais de contas. 6. ed. Belo Horizonte: Fórum, 2015.

LÔBO, P. Direito civil: parte geral. 4. ed. São Paulo: Saraiva, 2013.

MELO, C. A. B. Curso de direito administrativo. São Paulo: Malheiros, 2010.

SILVA, J. A. Aplicabilidade das normas constitucionais. 8. ed. São Paulo: Malheiros, 2012.

SOUZA NETO, C. P.; SARMENTO, D. Direito constitucional: teoria, história e métodos de trabalho. Belo Horizonte: Fórum, 2012. 